new fields we should avoid the manifest errors of our business predecessors. Agreeing with Dr. Johnson's astronomer that "the memory of mischief is no desirable fame," we should not seek, for example, to perform the academic feat of capitalizing deficits. Even if there were a body of alumni to which appeal might be made in distress, such a feat would be unworthy of a research organization. Above all, research organizations should embrace the great advantages that come from open audit and truthful publicity in all financial affairs. We should accept these and the other conditions and limitations of our environment to which attention has been called, not in a spirit of unreflective meekness, nor in a spirit of impatient defiance, but in a spirit of philosophic equanimity, confident that the scientific methods of observation, experiment, comparison, demonstration, generalization and verification will ultimately work out adjustments to the permanent advantage of our successors, if not to the ephemeral advantage of ourselves.

\section{R. S. WOODWARD}

\section{ADDRESSES AT THE DEDICATION OF THE NEW BUILDINGS OF THE MARINE BIOLOGICAL LABORATORY' 1}

THE subject of biology possesses immense significance for human thought and action. If the biology, the sociology, the philosophy and whole mode of thought of the twentieth century differ quite radically from those of the mid-nineteenth century, it is largely because the biological investigations of Lamarck, of Darwin and of many others founded the evo-

1 In addition to these shorter addresses and the address of Dr. R. S. Woodward, printed above, an address was made by Professor Edwin G. Conklin, of Princeton University, who, on account of his absence from the country, was unable to prepare it for publication. Mr. C. R. Crane, president of the board of trustees and donor of the building, presided and presented the speakers. lution theory, the future development of which is one of the main problems of biology.

The cell-theory, another great generalization of biology, revolutionized the study of pathology, the basis of medicine, besides furnishing the indispensable foundation for all future biolcgical studies. The conception of the physicochemical constitution of protoplasm, or living matter, is a third great contribution of biological science of inestimable significance for science and philosophy.

Biology is related to the most practical affairs of life: to medicine, of which it forms the indispensable foundation, to hygiene and public health, to many problems of agriculture and animal industry, and to fisheries problems. Economic entomology, parasitology, protozoology, etc., are practical branches of our great subject; not to mention the fundamental principles of the mooted subject of eugenics. The advancement of biology is one of the most important considerations of modern society.

Even such an intentionally incomplete statement of the significance of biology may appear exaggerated. But nothing is more sure than that the acquisition of knowledge increases man's control of nature, and that the science of biology, although still in an early stage of its development, promises control of those uncertainties of practical human life which are most perplexing and dangerous to the race.

The significance of the present occasion is to be found only partly in such general considerations. This laboratory represents one of the forces that have to be reckoned with in this general situation. But it is to the special significance of this occasion that I would more particularly direct your attention.

The sea-shore is undoubtedly the ideal situation for a biological station, because marine life offers certain valuable opportunities for study that are unique. These are given in such a situation as ours, and we relinquish none of the opportunities of inland laboratories. Louis Agassiz, in America, and Anton Dohrn, in Europe, were among the first to organize seaside laboratories; about the same time, 1872, Agassiz founded his station on the 
neighboring island of Penikese, and Dohrn his station in Naples.

This laboratory is in a very real sense a lineal descendent of Agassiz's station. Our immediate predecessor was the Annisquam Laboratory organized to serve the same ends as the Penikese school, and the forces there were supplemented and transferred to Woods Hole in 1888.

It is not sufficient that a laboratory should merely be established and equipped. It must be properly organized and manned. In some respects our laboratory has an unusual form of organization. As Mr. Crane has well said, Ireedom is its dominant character; the freedom of a democracy of learning. Our corporation, numbering 300 , extends into a large proportion of the institutions of learning of the country. Our board of trustees, chosen by the corporation, includes representatives of various branches of the biological sciences in many of our leading institutions. The laboratory is owned and controlled by the people whom it serves; and this is the essence of a democratic organization, the only assurance of freedom of development.

The laboratory thus organized stands for the advancement of the biological sciences by research and by teaching. We have not believed it wise to divorce these two functions of learning. The research creates an atmosphere in which teaching is most vital, and the teaching humanizes the research by bringing it constantly in contact with the needs of students, besides serving the essential function of training future investigators.

Freedom of organization is our one watchword. Cooperation is our other. Both are vital, and they are interdependent. When people are free those of similar interests naturally cooperate, so long as they respect freedom. And so we have a union of forces of scientific men, and through them of institutions that they represent in order to create conditions as ideal as possible for the progress of science.

The new building stands for a certain stage reached in the evolution of this democratic institution; it stands for recognition of a certain degree of demonstrated stability; and for a cer- tain amount of assurance of permanence. And so we rejoice in the present occasion, and have asked many of our friends to join with us in dedicating this building to the ideals of research, of teaching and of cooperation in freedom of spirit.

This magnificent building which we dedicate to-day is the most efficient instrument of research in the hands of biologists. For its beauty and enduring strength we are indebted to the great architect, Charles Coolidge, who rendered his services freely; and for its convenience, adaptability and sufficiency to Dr. Drew, with whom the perfection of every detail has been a labor of love.

We must not forget on this occasion to honor the memory of our greatest leader, Professor Whitman. I would that he had lived to see this day; and, as he valued the things of the spirit so infinitely above the material, I hope that he would find that the spirit of the present stage of our institution matches its material equipment.

\section{R. S. IILLIE}

I APPRECIATE the courtesy that has been extended to me by the invitation to attend these exercises. I have gladly accepted that invitation on behalf of the bureau I represent, because I feel it to be a pleasure that may properly be enjoyed and a duty that should not be neglected, to testify by my presence and words to the interest which the Bureau of Fisheries has in the opening of this new building and in the larger field of usefulness which is hereby presented to the Marine Biological Laboratory.

From Secretary Redfield I bring a cordial message carrying hearty congratulations, appreciation of the spirit which has actuated the dcnation of this magnificent edifice, sympathy with the past and future work of this institution, and the assurance of his desire to have the scientific activities of his department, here and elsewhere, in genuine cooperation with and in aid of biological research.

My dominant thoughts on this occasion are of those who once labored here but are no longer with us. I have been thinking of the satisfaction with which they would have en- 
tered into this day's exercises. I need not name all of them, but I recall, as you will, Peck, Ryder, Montgomery, Gardiner, and especially Whitman; and one other, the pioneer who really discovered the biological advantages of Woods Hole as early as 1869, and did as much as any one else to inaugurate the movement which has made this the most noteworthy American center for marine biological research. I refer, of course, to Spencer F. Baird.

I have been asked to speak of the cooperation that should exist between the Bureau of Fisheries and the biologists and their institutions; but that is too large a subject to handle adequately in the few minutes that have been allotted to me.

It is perhaps quite unnecessary for me to state that the Bureau of Fisheries is always ready to lend to biologists substantial aid and effective cooperation compatible with its functions and with the purposes for which it receives support from congress. The various phases of this cooperation need not be mentioned, but there may be cited, as an example, the scientific expeditions to which the $A l b a$ tross was assigned, under Agassiz, Jordan and others, which have resulted in larger additions to knowledge of the life of the sea than have come from any other source, not even excepting the Challenger.

On the other hand, many of the leading biologists of the country have rendered noteworthy service to the bureau in investigating fishery and cognate subjects. In the capacity of investigators for the bureau or as the recipients of the courtesies at its laboratories, on its vessels, or in the field, a very large proportion of the prominent American biologists of the last quarter of a century have cooperated in the furtherance of science. At the present moment we are favored by cooperative relations with the representatives of the biological departments of 10 state universities and of as many other front-rank universities, to say nothing of various other institutions of learning.

I will take this opportunity to call attention to the fact that, in addition to the two marine fisheries laboratories now maintained by the
Bureau at Woods Hole and Beaufort, it is expected that during the next year work will bo commenced on a third marine biological station, to be located at or near Key West, where the wonderful fauna of the Gulf Stream and of the abysses over which it flows, and of the coral reefs and the shoal waters back of them, will furnish unrivaled opportunities for research. Furthermore, if a bill now before congress should become a law, a fourth station will be established on a site which will render accessible for study under government auspices one of the rich biological regions of the $\mathrm{Pa}$ cific coast.

During the present summer there has been opened a fresh-water biological station, loeated on the Mississippi River at Fairport, Iowa. It has a large laboratory building, an abundant supply of crude and filtered river water, an extensive pond system and a general equipment that should render it an important factor in the study of the biology of the waters of the Mississippi Valley.

All of these laboratories are, or will be, freely open to qualified men of science, under such restrictions only as are required by good administration.

Here at Woods Hole, the friendly relations that already exist should be extended. The two laboratories have different functions and occupy different fields. There is no reason why any feeling of rivalry should exist. There is every reason why mutually helpful and close cooperation should prevail. Mention may be made of some of the ways in which the two institutions may profitably work together:

(a) Exchange of material where research is being conducted on a given subject at one laboratory and not at the other. For instance, the Bureau of Fisheries is now conducting at Beaufort, and will conduct next summer at Woods Hole, a comprehensive study of the post-embryonic development of economic fishes, a very important subject to which practically no attention has heretofore been given. Suitable material obtained by the Marine Biological Laboratory in its towings and otherwise would be valuable and most acceptable. 
(b) Exchange of information between the directors concerning the subjects under investigation at the respective laboratories, with the view to prevent duplication of work, but particularly to advantageously supplement at one laboratory work which in some of its phases may be under way at the other. For instance, certain work at the Marine Biological Laboratory may have economic connections which would not be given much consideration. Probably an investigator at the Fisheries Laboratory could be assigned to this side of the subject to the mutual advantage of both workers, economy of material and effectiveness of effort. Conversely, while the Fisheries Laboratcry is concerned with investigations more directly related to the fishing industry, there frequently arise in connection with them collateral, more abstract, problems which would perhaps appeal to investigators at the Marine Biological Laboratory.

(c) Reciprocal access to daily collections. It frequently occurs that when no one at a laboratory has an interest in a certain organism, or classes of organisms, the material collected is either thrown away or imperfectly cared for. If when the collections are brought in a competent person from the other laboratory, and familiar with its needs, could be given an opportunity to examine the collections, or at least the rejected material, much now wasted might be utilized.

(d) The effectiveness of the collecting could probably be increased by such cooperation as would prevent duplication in the fields covered. This could be arranged by an understanding of mutual requirements and the cooperation of the collectors.

I share the feeling entertained by many others that a new era in American biological science is now dawning; and that, under the inspiration and stimulus afforded by $\mathrm{Mr}$. Crane's noble gift, the day is not far distant when Woods Hole will come to be generally recognized abroad as well as at home as the world's biological Mecca.

HUGH M. SMTTH
TIME RATIOS IN THE EVOLUTION OF MAMMALIAN PHYLA. A CONTRIBUTION

TO THE PROBLEM OF THE AGE OF THE EARTH

Consmered as a historic science, geology has not yet solved its first problem. There is as yet no satisfactory way of estimating the age of the earth and the length of geologic periods. The various methods that have been devised to compute it are all subject to such large factors of uncertainty dependent upon questionable assumptions, that the most that can be claimed for them is that they indicate the order of figures which should be assigned as the antiquity of geologic periods. The relative length of the periods one with another can usually be more definitely gauged. But the translation into years is a matter of wide divergence of opinion and no real proof that any of the results are even approximately correct.

It is quite true that various estimates have been made by geologists and physicists resulting in figures which are of the same order of magnitude and in reasonably close agreement, although derived from independent sources. This might be taken as evidence that the age probably lies within these limits. But in fact it does not prove any such thing, for it rests in every case upon the assumption that the activities, whose accumulated results are the measure of the length of time that they have been in action, have proceeded in past times at the same pace as at present. This is not only unproved, there are strong reasons for believing it widely different from the fact.

There is no occasion to review these methods of computation or to point out other unprovable assumptions. Every competent discussion of the subject has sufficiently called attention to them.

What I have to contribute is the suggestion of a possible measure derived not from inorganic, but from organic evolution. It is approximate indeed, and relative, based like the others upon assumptions which can not be proven. But it is perhaps-I dare not say more-free or partially free from subjection to the varying intensity of inorganic activities 